\title{
Modelling Ground Source Heat Pump System by an Integrated Simulation Programme
}

Yi Rui ${ }^{1}$, Denis Garber ${ }^{2}$, Mei Yin ${ }^{3}$

${ }^{1}$ Dr. Yi Rui

Centre for Smart Infrastructure \& Construction, Department of Engineering, University of Cambridge, UK.

${ }^{2}$ Dr. Denis Garber

Department of Engineering, University of Cambridge, UK.

${ }^{3}$ Dr. Mei Yin

Schofield Centre, Department of Engineering, University of Cambridge, UK. 


\title{
Modelling Ground Source Heat Pump System by an Integrated Simulation Programme
}

\begin{abstract}
Ground Source Heat Pump (GSHP) is a technology which can be utilized to offer low carbon emissions heating/cooling and hot water supply. However, improperly designed GSHPs can increase operational costs and often do not provide the expected reduction in emissions. Under the current design approach in the industry, each of the GSHP system components is designed separately. To optimize the trade-offs between the different system components and to account for the uncertainty in thermal behaviour of ground and ground heat exchanger (GHE), we need an integrated approach that can model the system as a whole. In this paper, an integrated model of GSHP systems is developed and tested through a case study of an existing GSHP system in UK. In this integrated model, the GHE is simulated by a computational intensive finite element model, which can quantitatively predict the changes of temperature in the ground heat exchanger and surrounding soil. The close match between the modelled results and the actual data demonstrates the ability of the integrated model to simulate thermal-pile systems with a reasonable level of accuracy.
\end{abstract}

Keywords: Ground source heat pump, finite element, thermal pile

\section{Notation}

COP Coefficient of Performance

DAC Dry Air Cooler

FE Finite Element

GHE Ground Heat Exchanger

GSHP Ground Source Heat Pump

HP Heat Pump 
HVAC Heating Ventilation and Air Conditioning

LSOFT Load-Side-Outlet Flow Temperatures 


\section{Introduction}

According to DECC (2012a; 2012b; 2012c), the energy consumption for domestic heating accounts for $47 \%$ of the UK's carbon dioxide emissions and $60 \%$ of average domestic energy bills. The most recent data shows that approximately $80 \%$ of this heating energy is produced using fossil fuels. As global energy demand is forecast to increase by around $40 \%$ between 2007 and 2030, unless renewable technologies are implemented on a larger scale, the UK will be even more reliant on imported fossil fuels, and will be further exposed to global energy price fluctuations. Ground Source Heat Pump (GSHP) is a technology which offers an alternative energy solution that uses geothermal energy for space heating and cooling in a domestic and commercial market currently dominated by the use of fossil fuels. Generally, GSHP systems use soil, rock and ground water as a heat source or sink. The ground heat exchanger (GHE) of GSHPs is directly embedded in the ground, and is used to transfer heat into and out of the ground. In winter, the ground is used as a heat source to extract heat energy which can be used to heat buildings. In summer, a GSHP uses the ground as a heat sink to transfer the heat from buildings into the ground. However, this technology has only recently became more commonly used by the energy industry. This is partly due to the lack of reliable design tools, which can eliminate the design uncertainties which may affect the performance and efficiency of GSHP system.

The key components which need to be considered when designing a GSHP system with substructure GHEs are: the heating and cooling demand, the capacity and efficiency of the heat pump, the distribution system (heat emitters), any auxiliary systems, and the GHE. The various components of a GSHP system and the links between them are shown in Figure 1. Each component of a GSHP system is associated with a set of constants and time dependent variables that determine the performance of the system. In a GSHP system, the various elements of the system interact dynamically and there are many degrees of freedom in to the system, such that a parameter change in one component can affect the efficiency of other components and of the system as a whole. To better understand the overall performance of a 
complex GSHP system, it is therefore necessary to model the links and connections between its various elements.

Most integrated models reported in the past use a simplified ground exchanger model implemented in a building physics model such as TRNSYS (Magnier and Haghighat, 2000) or EnergyPlus (Sankaranarayanan, 2005). For example, Shonder and Hughes (1998) and Shonder et al. (2000) developed a model that considers the interactions between buildings, HPs and GHEs. The performance of this model was tested at Fort Polk, Louisiana, where the space conditioning systems of over 4,000 homes were replaced with GSHP, and at a public school in Lincoln, Nebraska. Yavuzturk and Spitler (2000) investigated the advantages and disadvantages of various operating systems and control strategies in a hybrid GSHP application using an hourly system simulation model under different climatic conditions. Fisher and Rees (2005) used the EnergyPlus program to conduct a multi-year simulation of GSHP operation using Eskilson's g-functions to model the response to time-varying heat fluxes, which they extended to include a computationally efficient variable time-step demand aggregation scheme. He and Lam (2006) evaluated a GSHP system with thermal piles that was recently built in China. In this study, simulations were carried out to study the failure of the system, using the TRNSYS simulation package. The TRNSYS platform was used by Zogou and Stamatelos (2007) to simulate the yearly performance of a residential building located in Greece, equipped with a conventional chiller and boiler system, compared to that of an alternative GSHP system. The comparative simulations demonstrated the expected transient and overall energy balance effects of the control settings, coefficient of performance (COP) characteristics, equipment sizes and other design parameters.

Several studies have been also carried out on the development and verification of integrated models for GSHP systems. These studies have demonstrated the advantages of integrated models in terms of system performance, and a better understanding of the trade-offs between different system components. Michopoulos and Kyriakis (2009) developed a tool for the energy analysis of vertical GSHP systems, and the model was then verified using actual electricity consumption data collected in Greece. In Spain, work was done by Magraner et al. (2010) to compare standard GSHP design procedures to experimental results. In addition, a hybrid system design in China was 
proposed by Fan et al. (2008). The system was tested using a mathematical model developed by the researchers, which is integrated with a water source HP and a building energy simulation program. In Japan, Miyata et al. (2007) developed a new simulation system by connecting an underground thermal model, which can simulate heat exchange between the ground and the pipes buried in the foundation piles, to models of the mechanical components in the air-conditioning system. Using the model, they were able to optimize the system performance.

However, most commercially available programs and the integrated models described above can only model conventional configurations of horizontal and vertical GHE pipes buried in the soil, and do not consider the change in ground temperature and interaction between neighbouring GHE pipes. It is a common sense that the thermal performance of the ground is a key factor in the design of GSHP systems, due to the significant effects of ground properties (conductivity, heat capacity and temperature distribution) on the efficiency of heat transfer between the GHE and ground. Most of the commercial GSHP design tools do not have the ability to accurately simulate these factors, especially the variation in ground temperature during the operation of GSHP system. Furthermore, those commercial tools are only concerned with the efficiency of the GSHP system and the amount of heat that can be extracted from or dumped into the ground and are unable simulate and predict the impact of a GSHP on the surrounding ground. However, the understanding of the distribution of the soil temperature around the GHE is often an important environmental constrain in the design of GSHP systems. There is, therefore, a need for a design simulation tool for such systems which can solve these questions. One possible approach is to develop an integrated GSHP simulation programme using a finite element GHE model that allows for the modelling of complex geometry and boundary condition, and hence gives an accurate prediction of the change in ground temperature and heat transfer between ground and GHE.

This paper presents an integrated GSHP model which incorporates a detailed GHE model. The main objective of this research is (i) to demonstrate the advantages of the integrated model and to highlight the complexity and interdependence of the various components of a GSHP system; (ii) to provide understanding of the importance of ground and GHE thermal 
performance and the associated parameters to the overall system performance; (iii) to investigate the effects of pile spacing and change in ground temperature on the efficiency of GSHP; (iv) to investigate the long-term performance of GSHP system.

\section{Background on the GSHP System in this Study}

In this paper, an integrated GSHP model is developed and evaluated at with a case study of an existing GSHP system installed at the One New Change Retail Centre in London. The One New Change Retail Centre consists of three basement levels and seven upper floors. It is located in a confined site with a total area of about $10,500 \mathrm{~m}^{2}$. As shown in Figure 2(a), it is located in the vicinity of several existing buildings. Thirteen (13) two stage reversible $130 \mathrm{~kW}$ capacity HPs are linked to GHE pipes incorporated into 124 foundation piles beneath the building footprint. The piles are $28 \mathrm{~m}$ long with a diameter of up to $2.5 \mathrm{~m}$. In addition to the thermal piles, two open-loop wells are installed at a depth of $75 \mathrm{~m}$ into the chalk aquifer, as shown in Figure 2(b). The two open wells are linked via a heat exchanger to the HP-source-side-return, as shown in Figure 2(b). The maximum allowed extraction from the open wells, based on environmental regulations, is $15 \mathrm{~L} / \mathrm{s}$ and $185,000 \mathrm{~m}^{3} /$ year, with a $10^{\circ} \mathrm{C}$ maximum temperature differential between intake and discharge. The estimated annual building heating and cooling demands are $1.4 \mathrm{GWh}$ and $1.8 \mathrm{GWh}$, respectively, and the GSHP system is predicted to provide $95 \%$ of these demands.

The control system uses the thermal pile circuits as the primary ground loop conditioning. If the thermal pile circuits cannot maintain the temperature of the ground loop within the desired temperature range of $5-25^{\circ} \mathrm{C}$, then the control system requests conditioning from either the Dry Air Coolers (DAC) or the open-loop circuit, as shown in Figure 3.

\section{The Integrated GSHP Model}

This section describes the integrated GSHP system model developed in this study to simulate 
the GSHP system at One New Change. The model was developed using an in-house finite element code of the GHE, which is linked to a model of the other system components (heat pumps, auxiliary heaters/chillers and the control system), as shown in Figure 1. The combined model was implemented using the $\mathrm{C}++$ programing language.

\subsection{Ground Heat Exchanger Model Using the Finite Element Method}

There are two important processes involved in the transfer of energy between the GHE and the ground. The first process is the heat and fluid coupling in GHE pipes. The second process is the heat transfer between the pipe flow, pile and ground. In this paper, the finite element method is used to solve the different partial differential equations for heat transfer. Figure 4 shows a schematic of the thermal pile system with a pipe network installed in the structural piles of a building and a finite element model of the pile. The model can be divided into three components: soil, pile, and pipe (pipe flow). Heat conduction solid element is used to model the heat transfer in soil and the pile. A 1D heat convection model is used to model the pipe flow within the pipes. The geometry of pipe wall is neglected, but its effect on heat transfer between pipe flow and pile is simplified as a heat transfer coefficient in the finite element model. Additional details on the model are provided in the appendix.

\subsection{Integrated GSHP Model for One New Change Retail Centre}

Figure 5 shows the flow chart of the integrated GSHP system model for One New Change retail centre. The calculation process is divided into the following ten steps, corresponding to the numbers in Figure 5.

\section{(1) Read Heating and Cooling Demand Data}

In this study, the building heating and cooling demands were represented with and hourly and daily demand schedule, which was based on the data collected from the actual system. Figure 6 shows the actual recorded monthly heating and cooling demands of the GSHP system at One New Change from April 2012 to July 2013. The actual hourly heating/cooling loads are used as input parameters in the integrated numerical model to simulate the short-term 
operation of the whole GSHP system. The daily heating/cooling loads are used as input parameters for long-term analysis.

\section{(2) Determine the Number of Operational HP and the Operation Mode}

In this paper, thirteen two stage reversible HPs are simulated for GSHP system. Each two-stage heat pump has a compressor which is capable of changing of heating/cooling mode every half an hour. Hence, the HP is able to supply both heating and cooling in each hour, improving its ability with greater precision. The simulation time step in this model is one hour, hence the calculation of time-varying parameters, like heat pump capacity, power consumption and COPs are based on one hour time steps. Hence the maximum number of activated cooling/heating stages of the total 13 HPs is 26 in one hour. According to the COP of GSHP system and auxiliary components, the control system adjusts the fraction of the total heating/cooling load provided by GSHP and calculates the total number of activated heating stages $\mathrm{N}_{\text {heating }}$ and total number of activated cooling stages $\mathrm{N}_{\text {cooling. }}$.

\section{(3) Determine whether Auxiliary Heating or Cooling System is Required}

The system evaluated in this study, does not provide the entire heating/cooling demand, but acts as the first and primary source of heating and cooling. When additional heating/cooling is required, gas-fired boilers and vapour-compression chillers provide the difference.

\section{(4) Determine Heat Pump Capacity, Power Consumption and COP}

The heat pump model is based on user-supplied data file containing catalogue data for the normalized capacity and power draw, based on the entering load and source temperatures and the normalized source and load flow rates. Data provided by the manufactures for the specific heat pump model evaluated in this study was used. The GHE outlet temperature, $\mathrm{T}_{\mathrm{gl}, \text { out }}$, determined from the GHE model is used as an input for the heat pump model.

The model uses bi-linear interpolation of the performance data to determine the following parameters: $\mathrm{CAP}_{2 \text { heating }}$ is heat output capacity of 2 stages of heating (in $\mathrm{kWhr}$ ) $\mathrm{CAP}_{2 \text { heating; }}$; $\mathrm{CAP}_{2 \text { cooling }}$ is heat output capacity of 2 stages of cooling (in $\mathrm{kWhr}$ ); $\mathrm{E}_{\text {elec,heating }}$ is power demand 
for 2 stages of heating (in $\mathrm{kWhr}$ ); $\mathrm{E}_{\text {elec,cooling }}$ is power demand for 2 stages of cooling (in $\mathrm{kWhr}$ ); $\mathrm{COP}_{\text {heating }}$ is Coefficient of performance of heating; $\mathrm{COP}_{\text {cooling }}$ is Coefficient of performance of cooling.

\section{(5) Determine the Source Side Temperature of Flow Exiting the HP}

The temperature of the flow leaving the HPs towards the ground loop is influenced by the heating/cooling supply values. The ground loop temperature $T_{\mathrm{gl}, \mathrm{in}}$ is calculated by the following equation:

$\mathrm{Q}_{\text {flow }}=\left(\mathrm{N}_{\text {heating }} * \mathrm{CAP}_{2 \text { heating }}+\mathrm{N}_{\text {cooling }} * \mathrm{CAP}_{\text {2cooling }}\right) / 3.5 * 11.4 * 60 / 1000$;

$\mathrm{T}_{\mathrm{gl}}=\mathrm{T}_{\mathrm{gl}, \text { out }}-\left(\mathrm{N}_{\text {heating }} *\left(\mathrm{CAP}_{2 \text { heating }}-\mathrm{E}_{\text {elec,heating }}\right)-\mathrm{N}_{\text {cooling }} *\left(\mathrm{CAP}_{2 \text { cooling }}+\mathrm{E}_{\text {elec, cooling }}\right) *\right.$ 3600/4.187/1000/ $\mathrm{Q}_{\text {flow }}$;

where $\mathrm{Q}_{\text {flow }}$ is the volumetric flow rate in the ground $\operatorname{loop}\left(\mathrm{m}^{3} / \mathrm{hr}\right) ; \mathrm{T}_{\mathrm{gl}}$ is the ground loop temperature; $\mathrm{N}_{\text {heating }}$ is total number of activated heating stages; $\mathrm{N}_{\text {cooling }}$ is total number of activated cooling stages.

\section{(6) Determine whether Open Loop or Dry Air Cooling Systems are Required}

The control system uses the thermal pile circuits as the primary ground loop conditioning. If the thermal pile circuits are unable to maintain the temperature of the ground loop $\mathrm{T}_{\mathrm{gl}}$ within the desired temperature range of $5-25^{\circ} \mathrm{C}$, then the control system requests additional conditioning from either the DAC system or the open-loop circuit, based on the availability and performance characteristics of the equipment. The maximum allowable extraction from the open-loop wells, based on environmental regulations, is $17 \mathrm{~L} / \mathrm{s}$ and $185,000 \mathrm{~m}^{3} /$ year, with a $10^{\circ} \mathrm{C}$ maximum temperature differential between intake and discharge. The finite element model calculates the heating/cooling capacity of the open wells based on these regulations. During periods of high rejection rates, the temperature at the extraction well remained largely unchanged. The extraction well therefore was represented in the model with a constant temperature of $14.5^{\circ} \mathrm{C}$. 
In this step, the GHE inlet temperature, $T_{\mathrm{gl}, \mathrm{in}}$, is calculated. The GHE inlet temperature is determined based on the flow-rate and the and flow-temperature exciting the HPs (which is determined in step 5) and any auxiliary energy rejected or extracted by the Open Loop or the DAC systems (determined in step 6).

\section{(8) GHE Simulation}

The finite element model is used to simulate the thermal piles. The inlet temperature $T_{\text {gl,in }}$ is used for the initial nodal temperature of the closed loop thermal pile circuits to calculate the outlet temperature $\mathrm{T}_{\mathrm{gl}, \mathrm{out}}$. A finite element mesh was generated to represent the geometry of the thermal piles, as shown in Figure 7.

Figure 7(a) shows a plan view of the mesh generated for the FE model. The dimension of the soil block is $450 \times 450 \mathrm{~m}$ and $150 \mathrm{~m}$ deep. Close to the building footprint the mesh is finer, and increases in size further away. There are a total of 192 foundation piles beneath the building footprint. The piles are $24-28 \mathrm{~m}$ long with a diameter of up to $2.5 \mathrm{~m}$. As shown in Figure 7(b), the soil block is divided into four layers: Made Ground, London Clay, Lambeth Group and Chalk Group. Figure 7(c) shows the 1D heat convection model used to simulate the heat transfer and fluid flow in the pipes. The thermal parameters are listed in Table 1. The conductivity of the London Clay layer, which is the layer in which the thermal piles are installed (excluding the made ground layer, consisting mainly of imported fill with known thermal properties), was determined based on a thermal response test done on site (Garber, 2014). The thermal properties of the other layer were assumed based on values available in the literature (Banks, 2009; Livingstone, 2010; Rollin, 1987).

\section{(9) Outputs of the GHE outlet temperature}

The primary outputs of the FE simulation is the GHE outlet temperature $\mathrm{T}_{\mathrm{gl}, \text { out }}$. This value is then used as an input for the HP model in the next time step (step 4).

\section{(10) Outputs of ground temperature}

The temperature distribution in the ground can also be outputted by the FE model, and the 
results can be used to evaluate the environmental impacts of the operation of GSHP.

\section{Results and Discussion}

\subsection{Model Validation}

The prediction of the integrated GSHP model were compared to the data collected over a period of 18 months from the GSHP system at One New Change.

Figure 8 shows the model and actual GHE inlet flow temperatures for the same time period. The dotted line shows the monitored GHE inlet flow temperature, the solid line shows the modelled GHE inlet flow temperature, and the dotted dashed line shows the modelled GHE outlet temperature. As Figure 8 shows, the FEM model is able to provide a reasonably good match with the actual monitoring data for the 18 month period.

As Figure 8 shows, over the period simulated in this study, the absolute difference between the inlet and outlet temperatures is about $1.0-2.5^{\circ} \mathrm{C}$. During the two winters (January to April 2012 and October to April 2013) the GHE outlet temperature is higher than the inlet temperature, which suggests that heat is absorbed by the fluid from the concrete/soil. During the two summers periods (May to September 2012 and May 2013 onwards), the GHE outlet temperature is lower than the inlet temperature, which indicates that heat is injected into the concrete/soil from the fluid.

Figure 9 shows a comparison between the HP power demand predicted by the model and the actual monitored data between February 2012 and July 2013. Some deviation between the two curves are expected due to uncertainties in some of the model inputs, such as the thermal properties of the pile and the ground, and the HP performance data. Over the period the model predictions matched to within $\pm 11 \%$ of the actual data.

The temperature distribution in the ground is shown in Figure 10. During weeks 10-30, due to 
the increase in cooling demand, heat is injected into the ground. The results clearly show that the temperature of the piles is higher than the temperature of the surrounding ground on week 20 and it keeps further increasing up to week 30. As Figure 10 shows, the temperature propagates outwards from the piles, and hence the temperature of the ground impacted by the temperature change propagates outward with time.

During weeks $50-70$ of the system operation, heat is extracted from the ground due to the increase in heating demand during winter, and therefore the ground temperature around the boreholes is lower than that of the surrounding soil.

As previously noted, the increase in ground temperature over time can be a potential environmental concern, and often needs to be controlled within a certain range. The modelling approach presented in this study, provides the ability to better understand the spatial distribution of the soil temperature around a GHE over time.

The temperature distribution in the GHE pipes after 30 weeks of operation is shown in Figure 11. The figure shows that the temperature of the pipe flow decreases from $30^{\circ} \mathrm{C}$ to $28.75^{\circ} \mathrm{C}$ along the direction of flow, which indicates that the pipe flow rejects heat to the pile and ground during this period of time.

\subsection{Effect of pile spacing}

There are a total of 124 thermal piles installed under the One New Change Retail Centre. The average distance between the piles is $9 \mathrm{~m}$. The thermal interaction between adjacent piles potentially has effect on the performance of the whole GSHP system. To assess the effect of pile spacing on the performance of the system, a series of finite element model analysis was performed by scaling up/down the FE mesh and pile spacing in horizontal direction. Except for the pile spacing, other pile and soil properties remained the same as described in the previous sections. Three different pile spacing configuartions are evaluated, $6 \mathrm{~m}, 9 \mathrm{~m}$ and $12 \mathrm{~m}$. 
Figure 12 shows the GHE-inlet temperatures for the different pile spacing. In general, the GHE-inlet temperature of all three cases increases during summer, and decreases in winter. With minimum pile distance $(6 \mathrm{~m})$, the GHE-inlet temperature is higher than for the other two cases after the first 20 weeks of operation. The highest inlet temperature at week 30 is about $37^{\circ} \mathrm{C}, 3^{\circ} \mathrm{C}$ higher than for the current system (pile spacing of $9 \mathrm{~m}$ ) and $5^{\circ} \mathrm{C}$ higher than for the $12 \mathrm{~m}$ pile spacing. The current GSHP system rejects more heat into the ground during the summer than it extracts in the winter, and therefore, with smaller pile spacing, the heat accumulates around the pile and the ground temperature increase more than for the other two cases, as shown in Figure 13. Hence, the GSHP system needs to increase GHE inlet temperature to meet the same cooling demand. The difference in both GHE inlet temperature and ground temperature close to the piles between the cases is larger during weeks 30 to 50 (the cooling period). However, this difference decreases after the winter, due to the fact that the heat, which was stored in summer, is extracted to meet heating demand in winter.

Figure 14 shows the electricity demand for different pile spacing. The inlet temperature of the case with pile spacing of $6 \mathrm{~m}$ is higher than for the other two cases especially from week 20 to week 60. Hence, the GSHP system with smallest pile spacing has a lower cooling COP but a higher heating COP than the other two cases. In the first year summer season (weeks 20-30), due to the high cooling demand, the lower cooling COP results in a higher electricity demand. However, in the winter time (week 45-65), the sharp increase in heating demand results in a lower electricity demands due to the lower heating COP as compared to the other two cases. Hence, the influence of change in pile spacing on the overall efficiency of the system during one full year of operation is small. It can be concluded that pile spacing has a large effect on the performance of GSHP system with heating or cooling demand only, due to the accumulated imbalance in ground temperature. But for the GSHP system with a well-balanced cooling and heating demand, the effect of pile spacing is less significant. 


\subsection{Evaluation of Future System Performance}

Once satisfactory results were achieved between the predictions of the integrated model and the data collected from the actual system, the FEM model was used to evaluate the system performance over a 30-year lifetime. The actual heating and cooling loads were used as inputs (the loads were assumed to be the same for every year) and it was assumed that the system control operated as designed.

Figure 15 shows the predicted GHE inlet temperature for the 30-year period. The weekly average inlet temperature decreases in years 1-10 and then approaches a steady state, with a minimum GHE inlet temperature being around $10^{\circ} \mathrm{C}$ and the maximum around $32^{\circ} \mathrm{C}$. The temperature is higher at the beginning of the system operation due to heat imbalance during the first several years, and there is an annual net heat rejection into the ground.

Figure 16 shows the predicted annual heating and cooling energy supplied by the GSHP over the 30 years. From years 3 to 12 , the cooling energy slightly increases while the heating energy decreases. From year 13 onwards, the heating energy supplied by the GSHP is about $1.75 \mathrm{GWh}$ and the cooling energy is about $1.3 \mathrm{GWh}$, and the difference between the energy extracted and rejected from the GHE approaches a steady state.

Figure 17 shows the annual heating and cooling HP coefficients of performance. As the GHE inlet temperature decreases, the HP cooling coefficient of performance improves but the heating coefficient of performance is reduced.

The operational costs, energy input and the associated $\mathrm{CO}_{2}$ emissions of the GSHP system over a 30-year life time period were compared to those of a conventional heating/cooling plant which meets the same annual heating and cooling loads. For the conventional plant it was assumed that the demand is met by a condensing gas-fired boiler ( $90 \%$ efficiency) and a vapour-compression chiller (COP of 4.0 ). The current average price of $£ 0.145 / \mathrm{kWh}$ for electricity and $£ 0.048 / \mathrm{kWh}$ for gas and a $\mathrm{CO}_{2}$ intensity of $0.420 \mathrm{~kg} / \mathrm{kWh}$ for electricity and 
$0.194 \mathrm{~kg} / \mathrm{kWh}$ (combusted) for gas was used (DECC 2013). Table 2 shows the total energy input, cost and $\mathrm{CO}_{2}$ emissions for the current system and the conventional system for a 30 -year lifetime. The table shows that the GSHP system provides more than 50\% reduction in the energy demand. It therefore satisfies the current planning requirements in London, which aim to reduce the energy consumption of new developments. It is important to note that the savings shown are operational costs savings only, and the extra capital costs of the GSHP system are not taken into account. It is therefore possible that the net cost savings of the system are marginal.

\section{Conclusions}

Currently the various components of a GSHP system are sized independently by different designers. Commercial GSHP design software packages focus on the design of the GHE, and assume the inputs from other components (building demand, HP performance specifications, distribution temperature etc.) as parameters. This design approach often leads to oversized systems and limits the ability of designers to optimize operation strategies and thus improve overall system efficiency, due to the lack of information about the change in temperature distribution and thermal performance of the ground.

The use of a GHE simulation model in an integrated modelling environment, presented in this paper, is a powerful tool in assessing the behaviour and dynamics of GSHP and hybrid GSHP systems. The integrated modelling approach allows implementation of sophisticated (based on small time intervals) operating and control strategies and incorporates a FE model which simulates the operation of GSHP system as well as predicts the changing temperature of the ground.

The good match between the model results and the actual data demonstrates the ability of the FEM code to simulate thermal pile systems to a reasonable level of accuracy. The main advantages of the FEM code are its flexibility and its ability to model non-conventional 
geometries for heat exchanger foundations or thermal piles distributed in a complex grid. The FEM model provides an insight into the behaviour of individual piles, local temperature propagation, and temperature variation in the soil, all of which may have large impact on the performance of GSHP system. In addition, the parametric study shows that pile spacing has a large effect on the performance of GSHP system with heating or cooling demand only, due to the accumulated imbalance in ground temperature. But for the GSHP system with a well-balanced cooling and heating demand, this effect becomes limited.

The integrated modelling approach in this study was used to evaluate the system performance over a 30-year life time period. The long term analysis indicates that the system and the annual temperature fluctuations around the GHE approach a steady state after 12-13 years of operation. A comparison between the current system and a conventional heating and cooling system over a 30-year lifetime suggests that the GSHP system provides over 50\% reduction in the energy demand.

\section{Appendix Finite element model for a GHE}

The pipe length is large enough that the flow inside can be considered to be fully developed. The flow behaviour can be simplified as a single tangential average velocity component along the edges, which avoids having to mesh the cross-section of the pipe. This means that the modelled variables are averaged across the pipe's cross-section and vary only along the length of the pipe. The mechanism of heat fluid can be derived from the conservation of heat energy, as shown in Figure A-1(a).

Hence, the mathematical model for heat transfer in pipe fluid is expressed as:

$$
\frac{\partial T}{\partial x} c_{w} V_{w}+k_{t r}\left(T-T_{s}\right)-D \frac{\partial^{2} T}{\partial x^{2}}+\frac{d T}{d t} c_{w}=0
$$

Where $\mathrm{T}$ is the average temperature of the pipe flow, $\mathrm{c}_{\mathrm{w}}$ is the specific heat of the fluid, $\mathrm{D}$ is the heat conduction coefficient of the fluid, $\mathrm{k}_{\mathrm{tr}}$ is the heat transfer coefficient between the pipe fluid and the pile, and $\mathrm{T}_{\mathrm{s}}$ is the temperature of the outer surface of the pipe wall (pile-pipe interface). 
Figure A-1(b) shows the finite element model for the simulation of heat transfer in a liquid flowing through a pipe. The solid line in the middle is the 1D line element used for the simulation of heat transfer in a liquid flowing through a pipe, which is coupled with the solid elements (concrete/soil) through nodes. Nodes i, j, k, 1, m, and n are duplicate nodes. Each set contains a fluid element node and a solid element node. They are different nodes which coincide.

\section{Acknowledgement}

We would like to thank Professor Kenichi Soga, (UC Berkeley) and Dr Ruchi Choudhary (Cambridge) for their active encouragement, support, patience, and guidance throughout this study.

\section{Reference}

Banks, D. (2009). An introduction to 'thermogeology' and the exploitation of ground source heat. Quartely Journal of Engineering Geology and Hydrogeology, 42:283-293.

Fan, R., Jiang, Y., Yao, Y., \& Ma, Z. (2008) Theoretical study on the performance of an integrated ground-source heat pump system in a whole year. Energy, 33(11), pp1671-1679.

Fisher, D. E., \& Rees, S. J. (2005, August) Modeling ground source heat pump systems in a building energy simulation program (EnergyPlus). In 9th International IBPSA Conference, Montreal, Canada, pp. 311-318.

Garber, D. (2014) Ground source heat pump system models in an integrated building and ground energy simulation environment. Doctoral dissertation, University of Cambridge. 
He, M., \& Lam, H. N. (2006) Study of geothermal seasonal cooling storage system with energy piles. Proceedings Ecostock.

Livingstone, P. M. (2010). An Investigation into the Suitability of Air and Ground Source Heat Pumps to the UK environment with a Swimming Pool Complex Heat Pump Installation.

Magnier, L., \& Haghighat, F. (2010) Multiobjective optimization of building design using TRNSYS simulations, genetic algorithm, and Artificial Neural Network. Building and Environment, 45(3), pp 739-746.

Magraner, T., Montero, Á., Quilis, S., \& Urchueguía, J. (2010) Comparison between simulation and experimental results for a monitored ground coupled heat pump system. In Proceedings of the World Geothermal Congress.

Michopoulos, A., \& Kyriakis, N. (2009) A new energy analysis tool for ground source heat pump systems. Energy and Buildings, 41(9), pp 937-941.

Miyata, M., Yoshida, H., Aono, M., Takegawa, T., Nagura, Y., Kobayashi, Y., \& Kim, J. (2007) Optimal operation for HVAC system with seasonal underground thermal storage system. In Building Simulation (Vol. 2007, pp. 1991-1998).

Rollin, K. E. (1987). Catalogue of geothermal data for the land area of the united kingdom. Technical report, British Geological Survey, UK.

Shonder, J. A., \& Hughes, P. J. (1998) Increasing confidence in geothermal heat pump design methods. Richard Stockton College of New Jersey.

Shonder, J. A., Martin, M. A., Hughes, P. J., \& Thornton, J. (2000) Geothermal heat pumps in K-12 schools: A case study of the Lincoln, Nebraska schools. US Department of Energy Publications, 30 . 
UK Department of Energy and Climate Change (DECC), (2012a. 2011) UK Greenhouse Gas Eemissions, Provisional Figures.

UK Department of Energy and Climate Change (DECC), (2012b) Detailed analysis from the first phase of the Energy Saving Trust's heat pump field trial, Energy Savings Trust.

UK Department of Energy and Climate Change (DECC) (2012c) Heat Emitter Guide for Domestic Heat Pumps.

Yavuzturk, C., \& Spitler, J. D. (2000) Comparative study of operating and control strategies for hybrid ground-source heat pump systems using a short time step simulation model. Ashrae transactions, 106, 192.

Zogou, O., \& Stamatelos, A. (2007) Optimization of thermal performance of a building with ground source heat pump system. Energy conversion and management, 48(11), pp 2853-2863. 
Table 1. Values of thermal properties

Table 2. 30-year total energy input, cost and $\mathrm{CO} 2$ emissions for conventional and current systems

Figure 1. Diagram of the links between the various components of a typical hybrid GSHP

Figure 2. Finite element model of the One New Change Retail Centre: (a) Plan view;

(b) Side view

Figure 3. Schematic diagram of the GSHP system (Garber, 2013)

Figure 4. (a) Schematic cross-section of the energy pile; (b) FE model of the thermal pile: (i) Pile and ground; (ii) Pipe

Figure 5. Flow chart of the integrated GSHP system model

Figure 6. Actual cooling and heating demands

Figure 7. Finite element model: (a) Plan view; (b) Cross-sectional view; (c) Pile model embedded in concrete piles (the red line indicates the pipe and the direction of the fluid flow)

Figure 8. Inlet and outlet temperature of the thermal piles

Figure 9. HP electricity demand: model predictions vs. actual data

Figure 10. Temperature distribution in the ground for the first year

Figure 11. Temperature distribution in the pipes (after 30 weeks)

Figure 12. Changes in GHE inlet temperature with variation in pile distanceFigure 13. Temperature distribution in the ground with time and variation in pile distance

Figure 14. Changes in electricity demand with variation in pile distance 
Figure 15. Predicted 30-year GHE-inlet temperature

Figure 16. Projected 30-year annual heating (grey) and cooling (black) demand supplied by the GSHP

Figure 17. Projected 30-year annual heating (grey) and cooling (black) coefficients of performance

Figure A-1. (a) Mechanism of heat transfer in fluid flowing in a pipe; (b) Finite element model for heat transfer between pipe flow and concrete/soil 


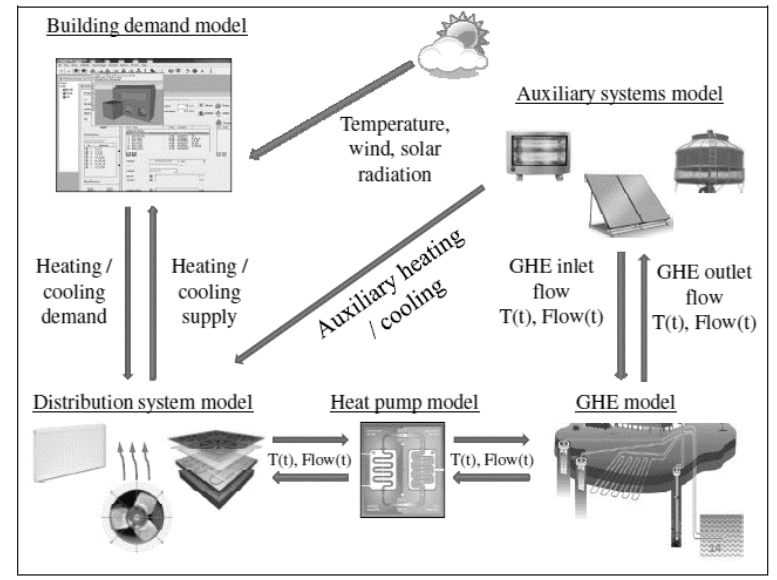

Figure 1. Diagram of the links between the various components of a typical hybrid GSHP

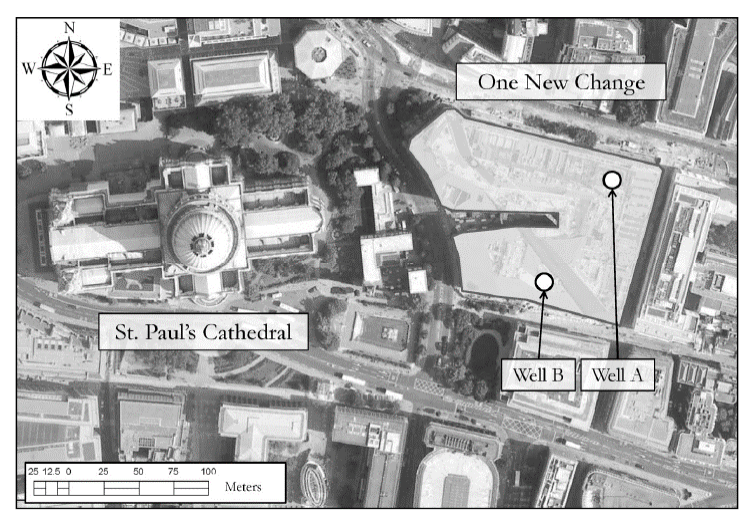

(a)

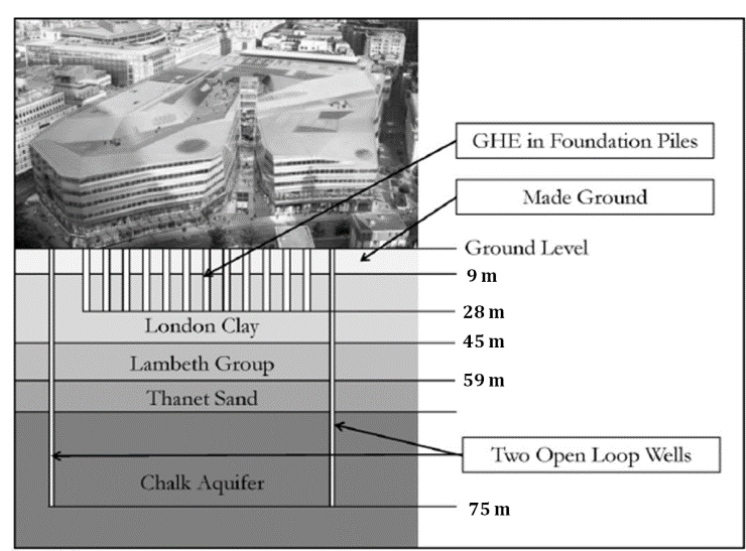

(b)

Figure 2. Finite element model of the One New Change Retail Centre: (a) Plan view; (b) Side view 


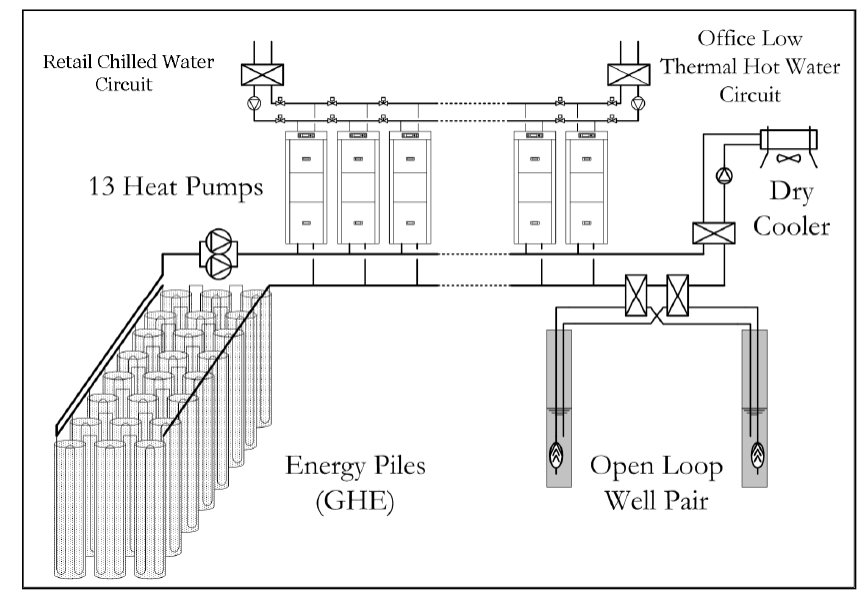

Figure 3. Schematic diagram of the GSHP system (Garber, 2013)

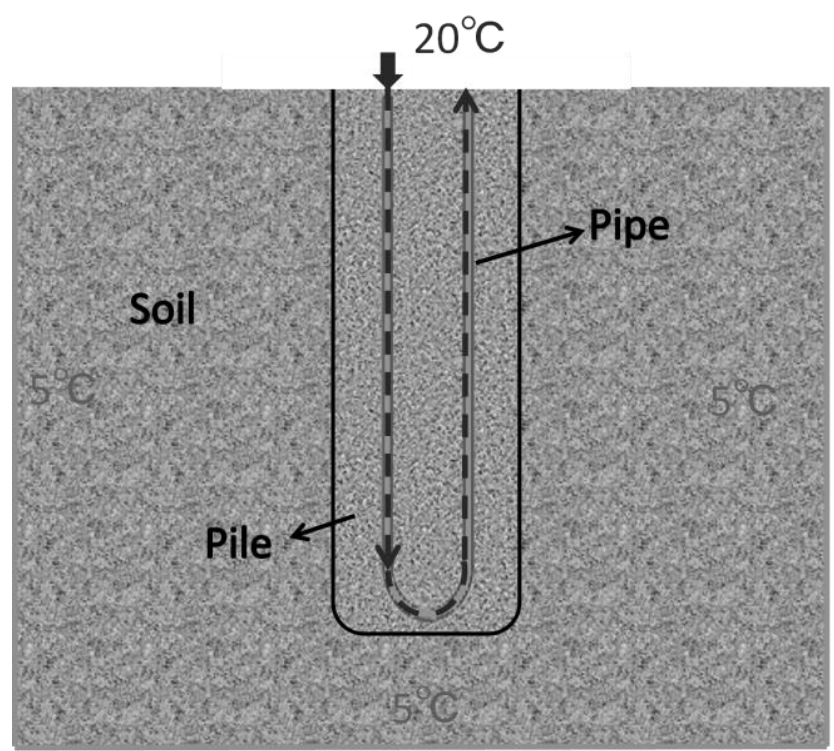

(a)

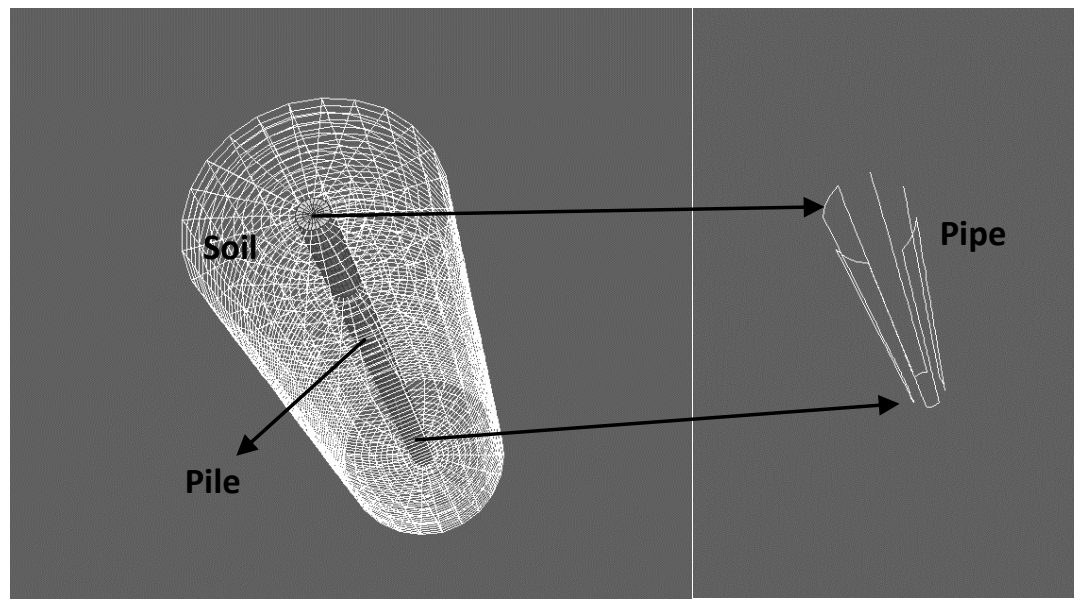

(i)

(ii)

(b)

Figure 4: (a) Schematic cross-section of the energy pile; (b) FE model of the thermal pile: (i) Pile and ground; (ii) Pipe 


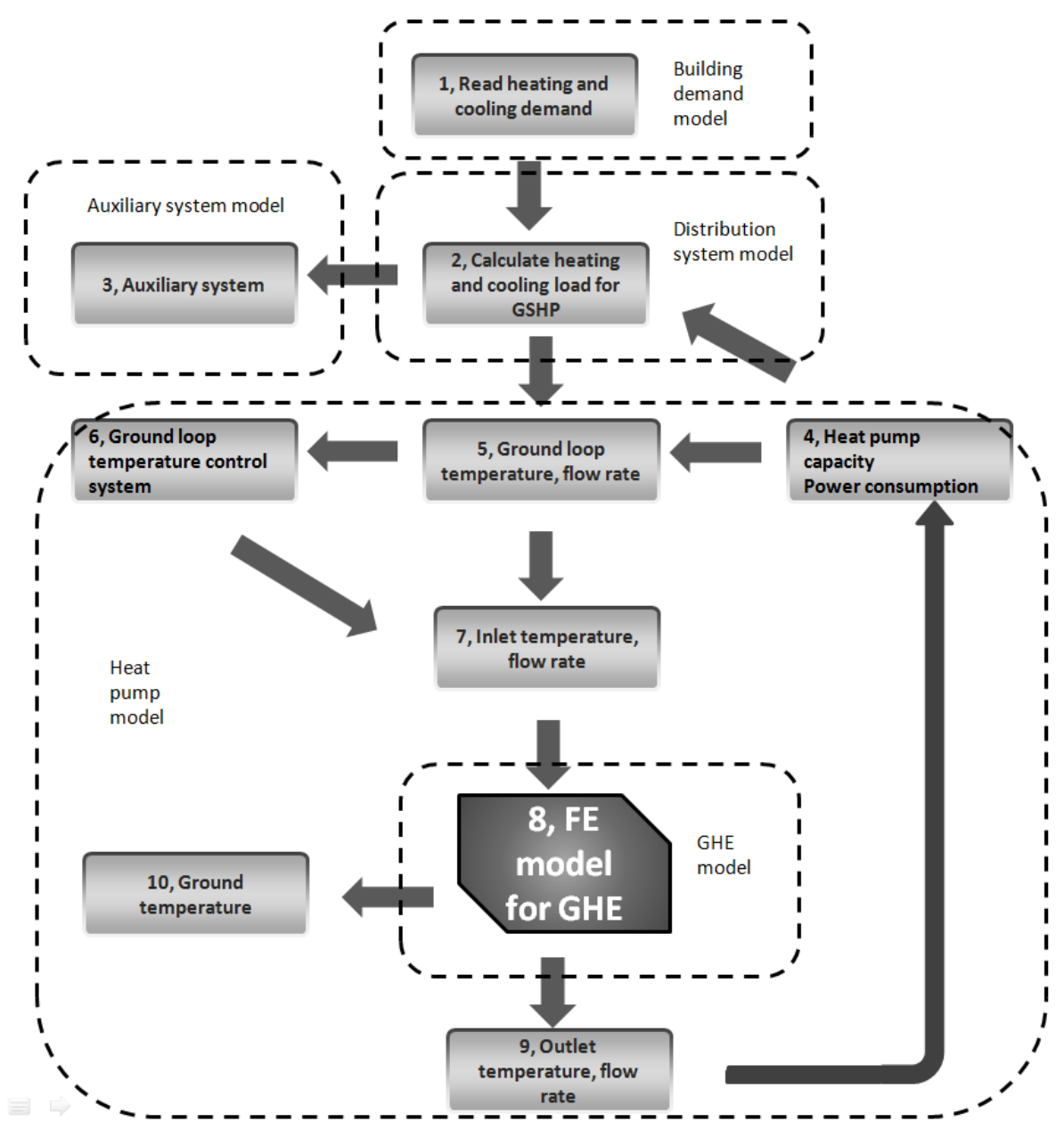

Figure 5. Flow chart of the integrated GSHP system model

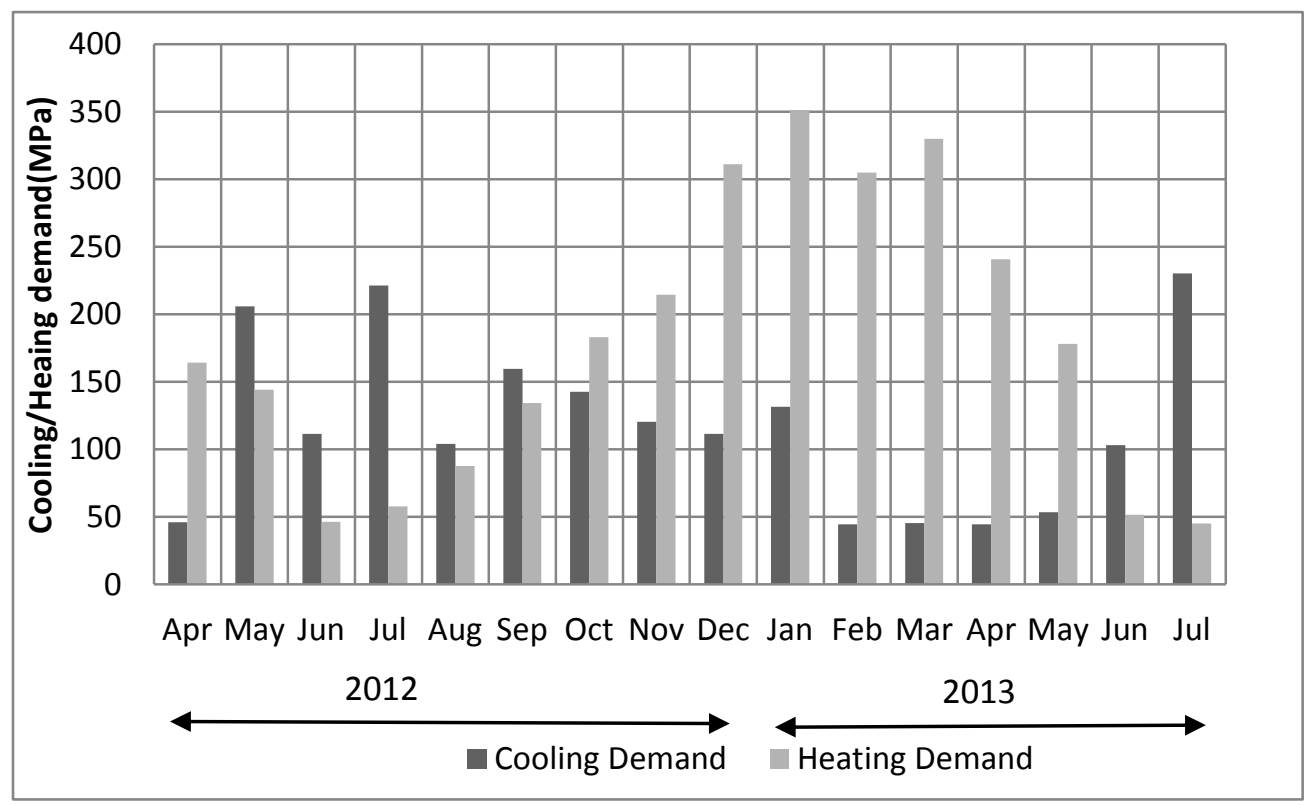

Figure 6. Actual cooling and heating demands 


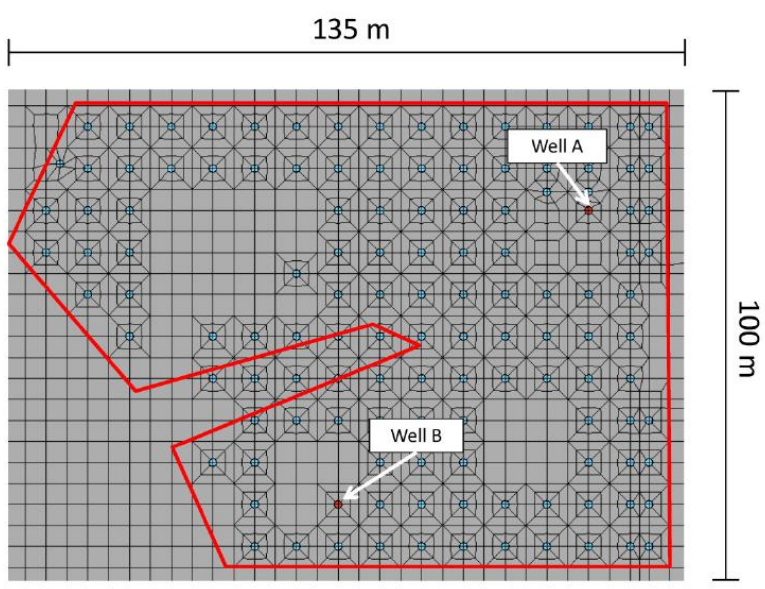

(a)

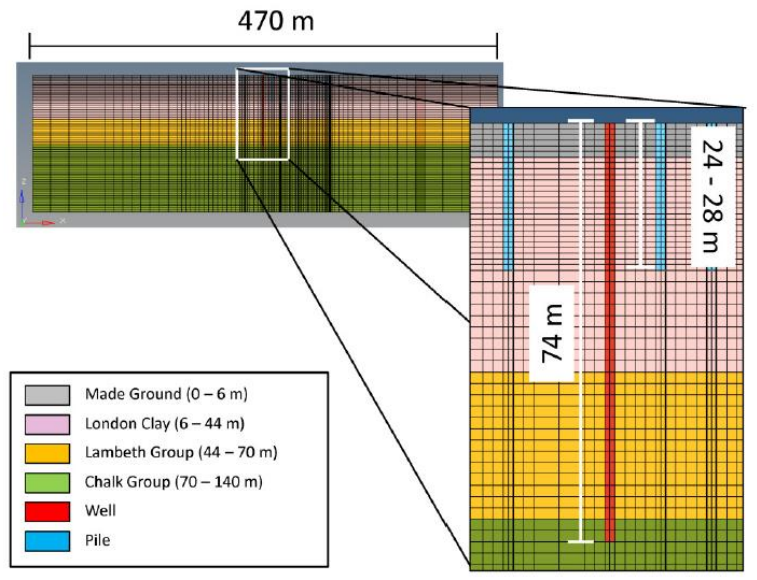

(b)
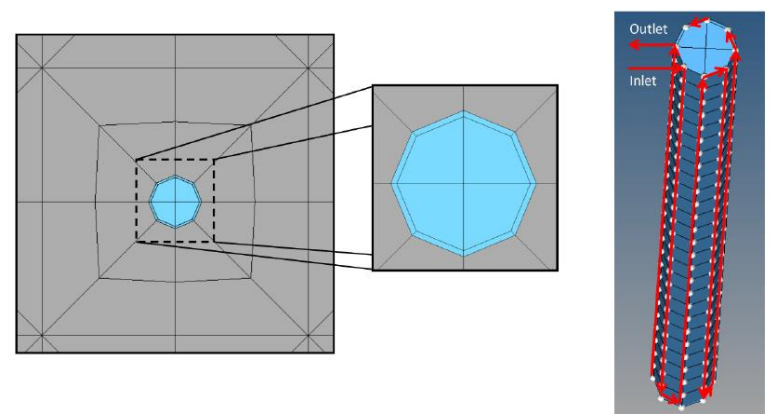

(c)

Figure 7. Finite element model: (a) Plan view; (b) Cross-sectional view; (c) Pile model embedded in concrete piles (the red line indicates the pipe and the direction of the fluid flow) 


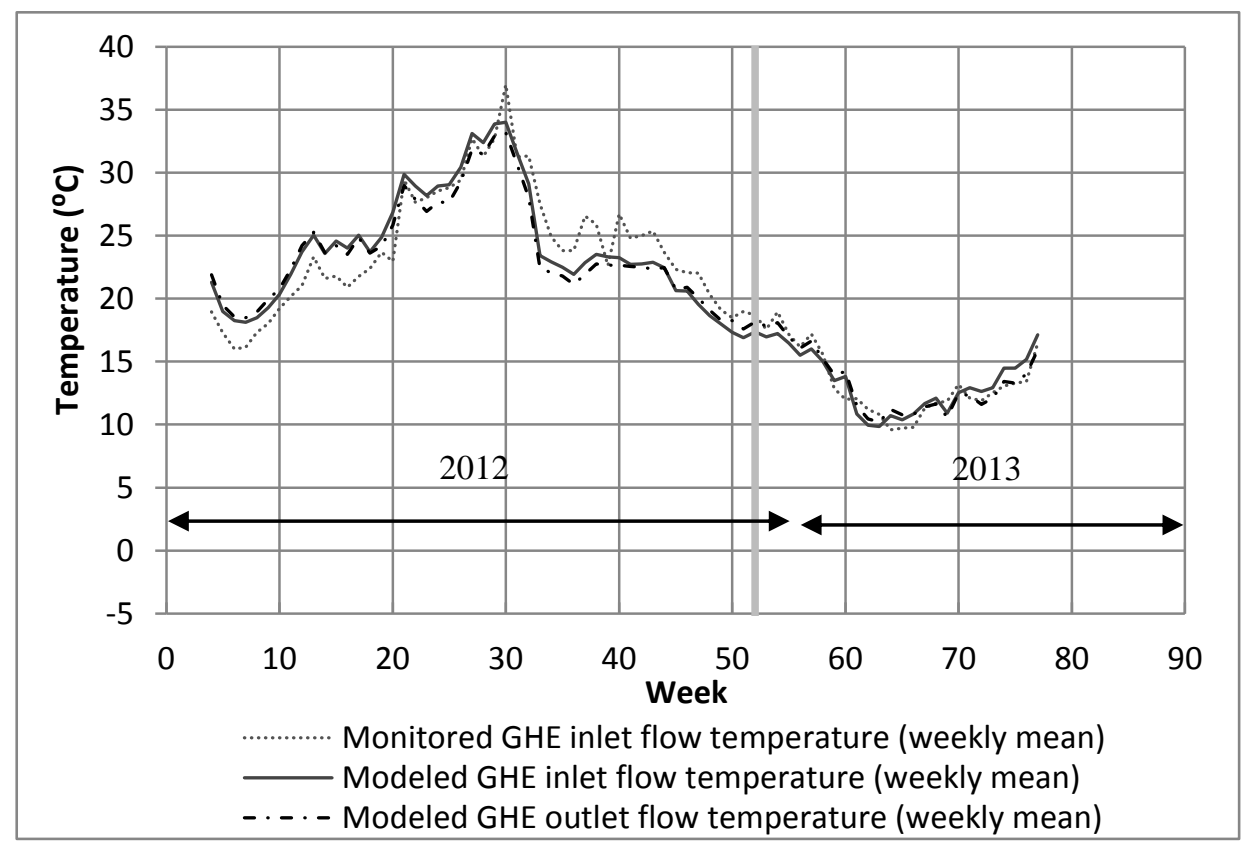

Figure 8 . Inlet and outlet temperature of the thermal piles

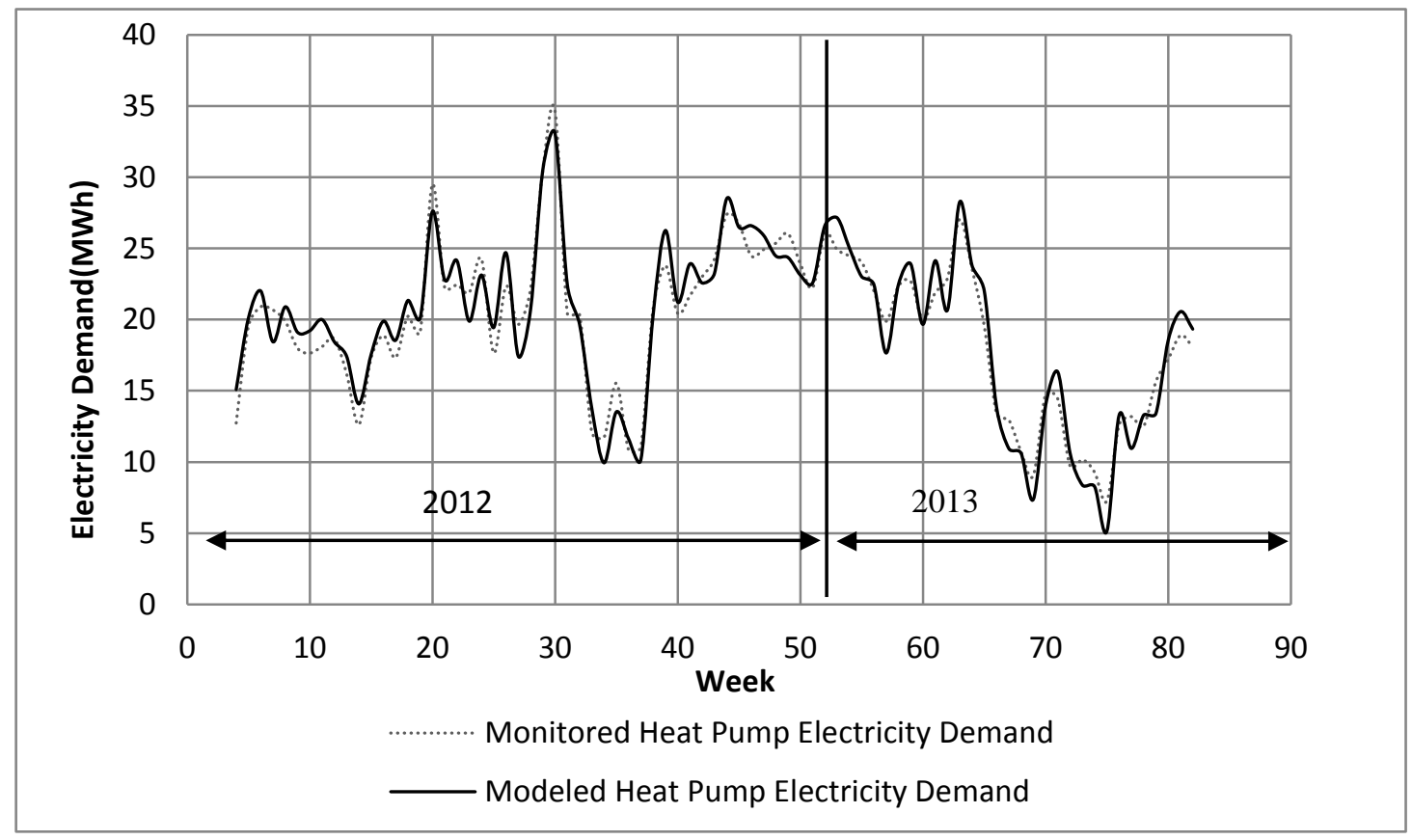

Figure 9. HP electricity demand: model predictions vs. actual data 


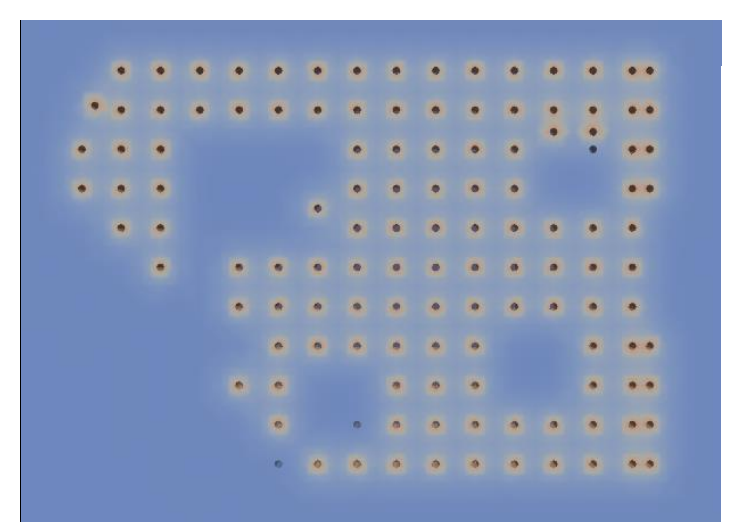

Week 10

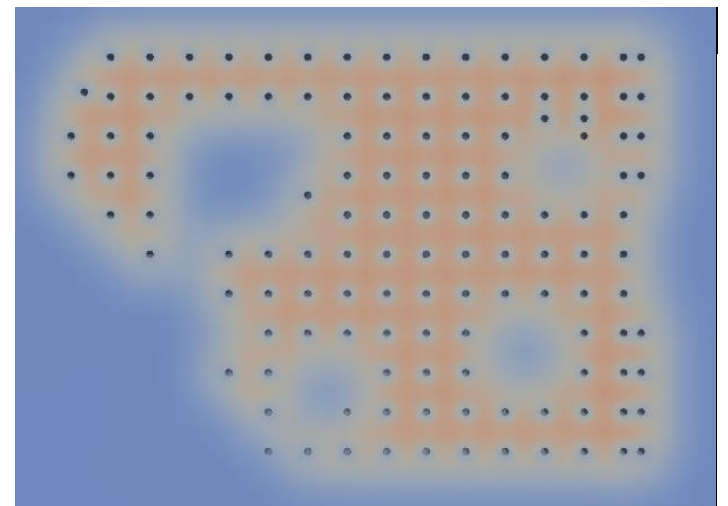

Week 50

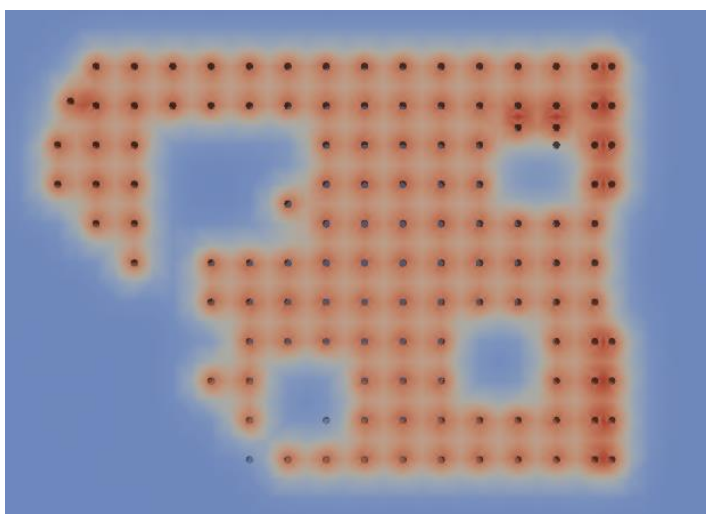

Week 30

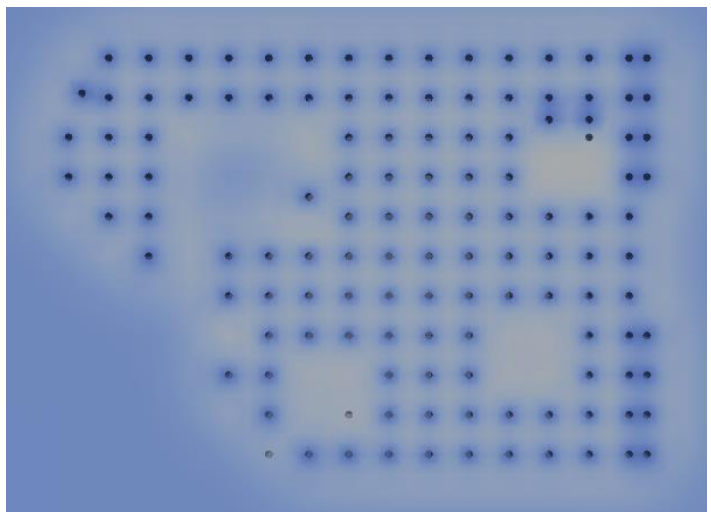

Week 70

$26 \quad 28 \quad 3.0 e+01$

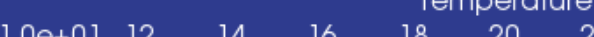

$\begin{array}{llllllllll}1 & 1 & 1 & 1 & 1 & 1 & 1 & 1 & 1 & 1\end{array}$

Figure 10. Temperature distribution in the ground

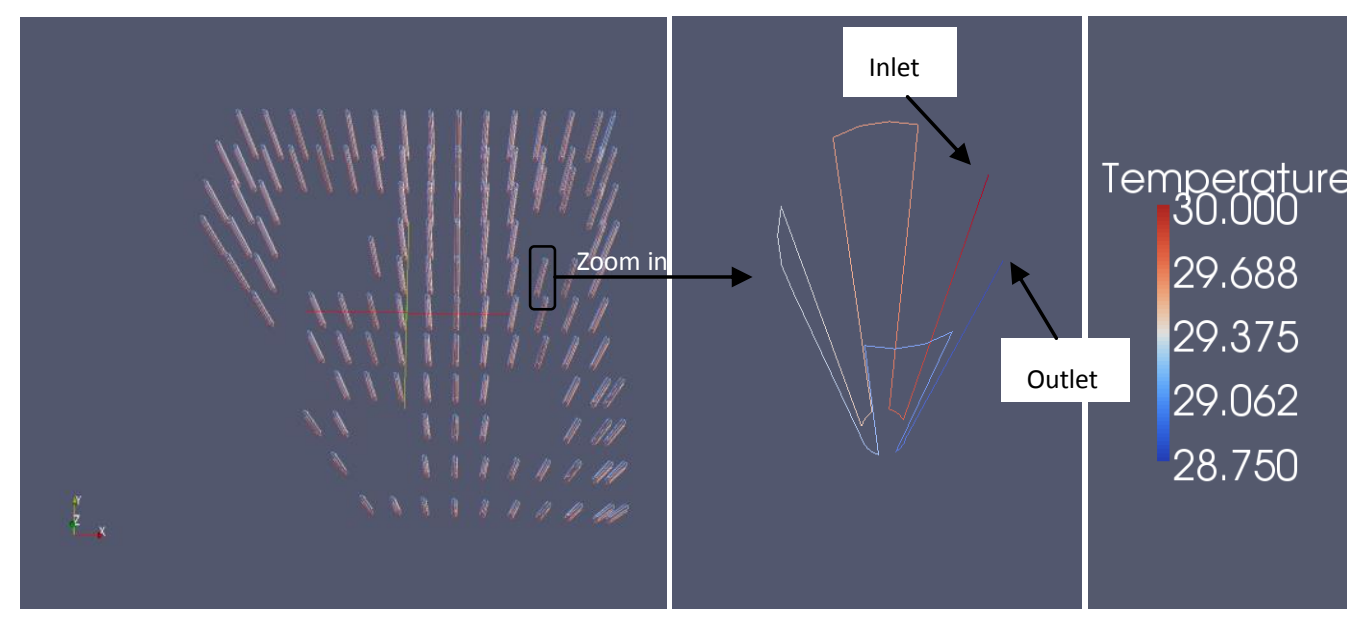

(b)

Figure 11. Temperature distribution in the pipes (week 30) 


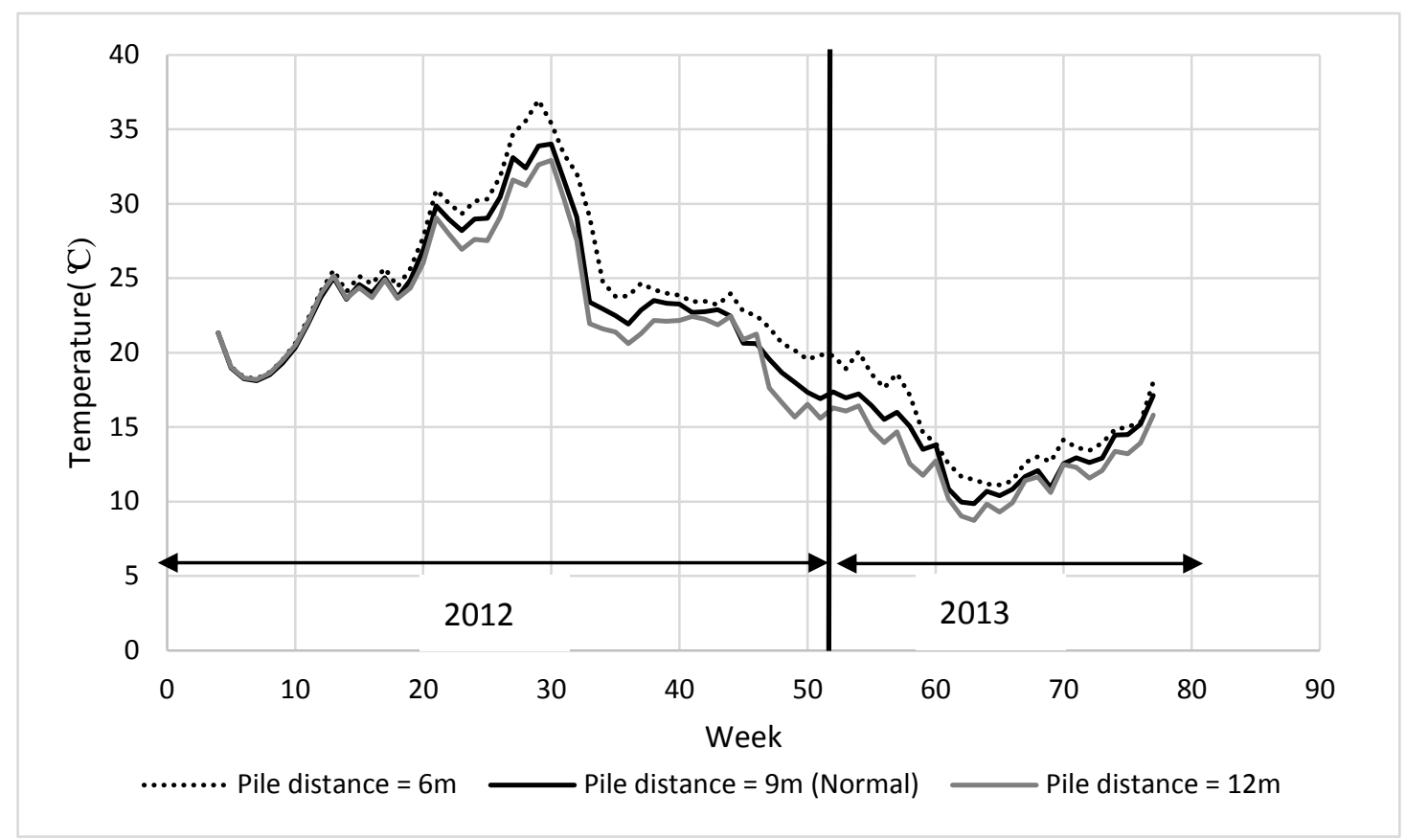

Figure 12. Changes in GHE inlet temperature with variation in pile distance

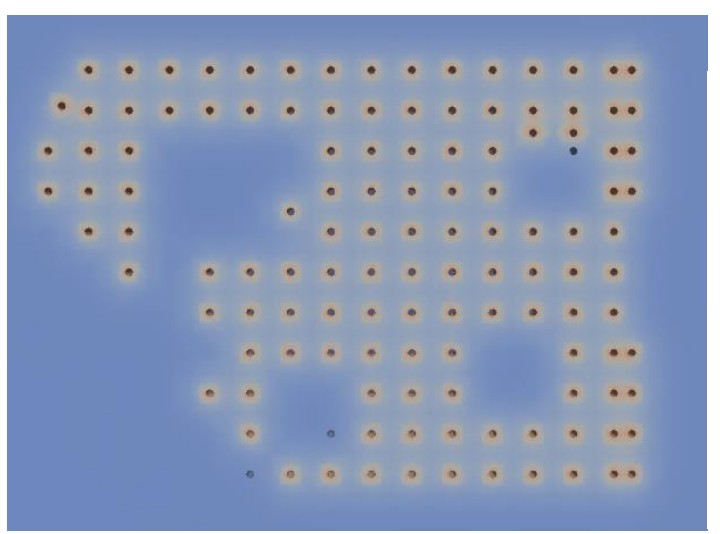

Week $10(6 \mathrm{~m})$

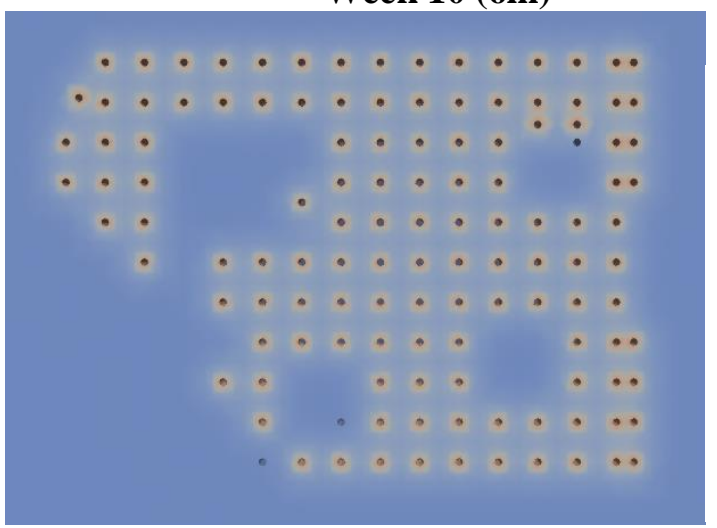

Week $10(9 \mathrm{~m})$

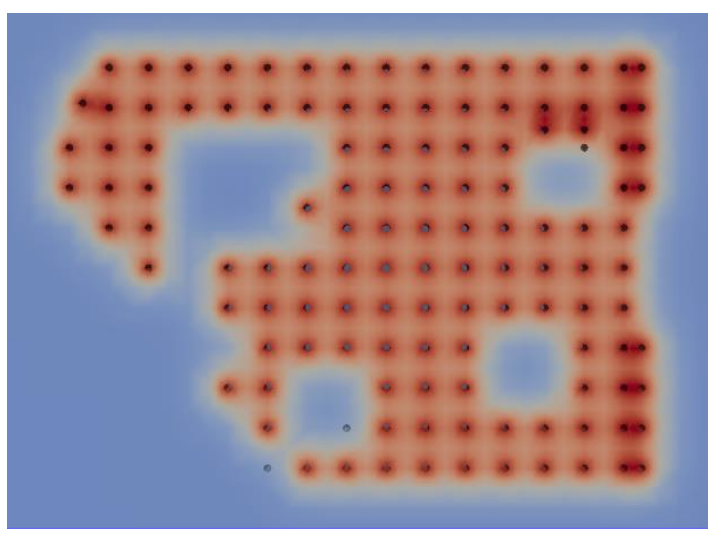

Week $30(6 \mathrm{~m})$

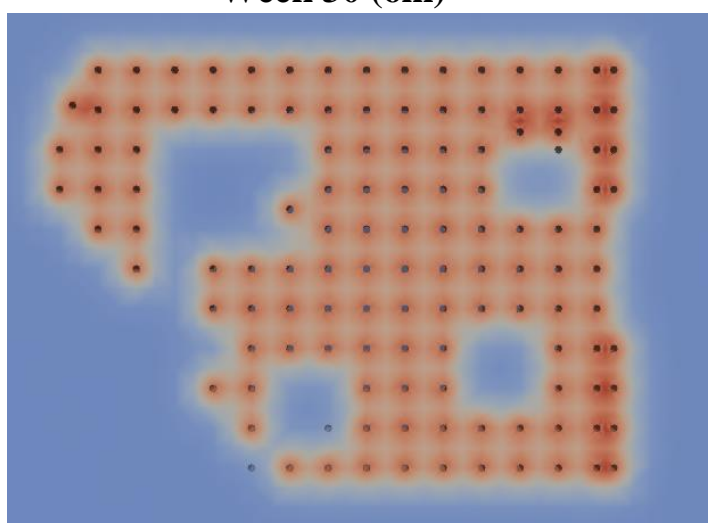

Week $30(9 \mathrm{~m})$ 


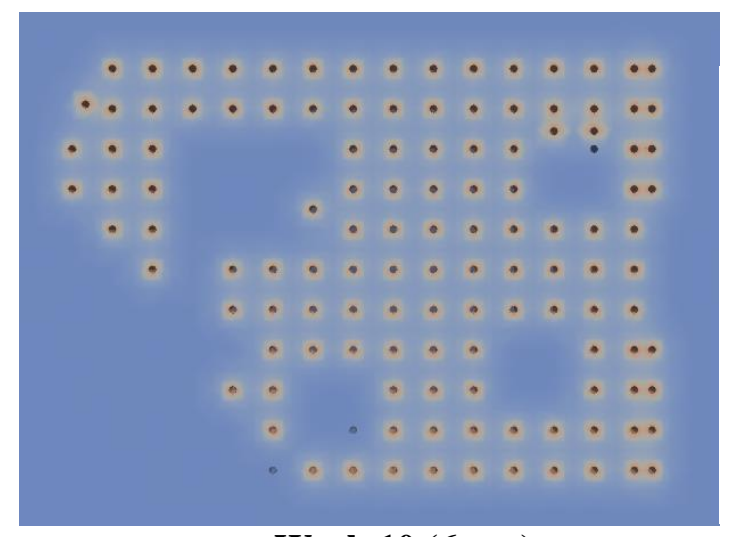

Week $10(6 \mathrm{~mm})$

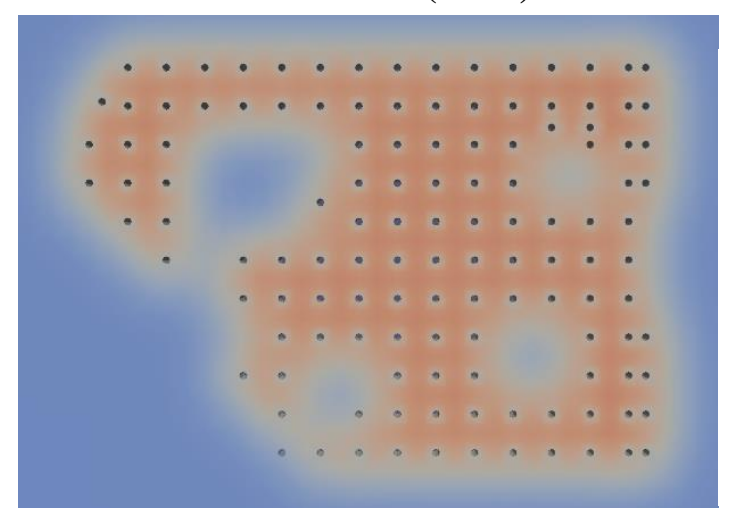

Week $50(6 \mathrm{~m})$

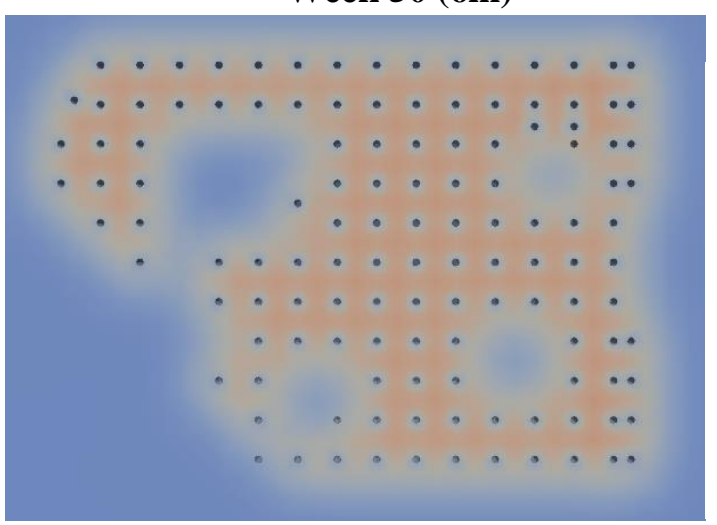

Week $50(9 \mathrm{~m})$

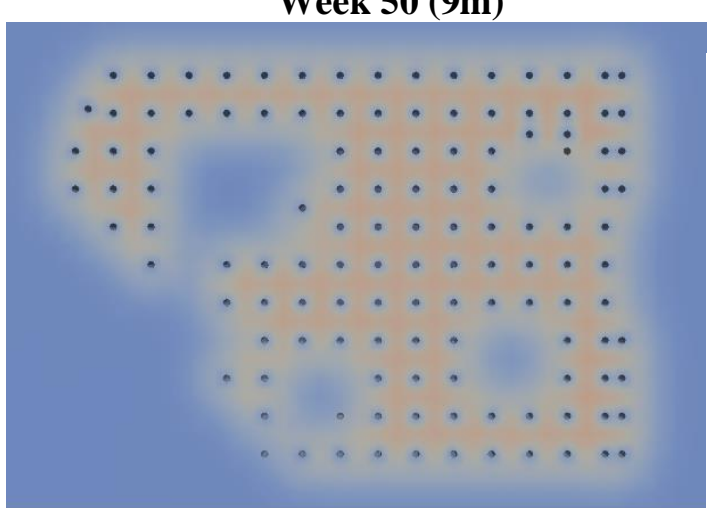

Week 50 (12m)

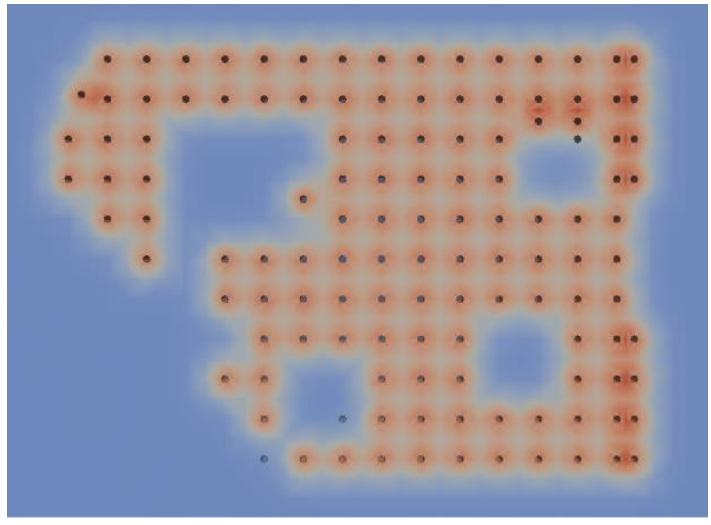

Week $30(12 \mathrm{~m})$

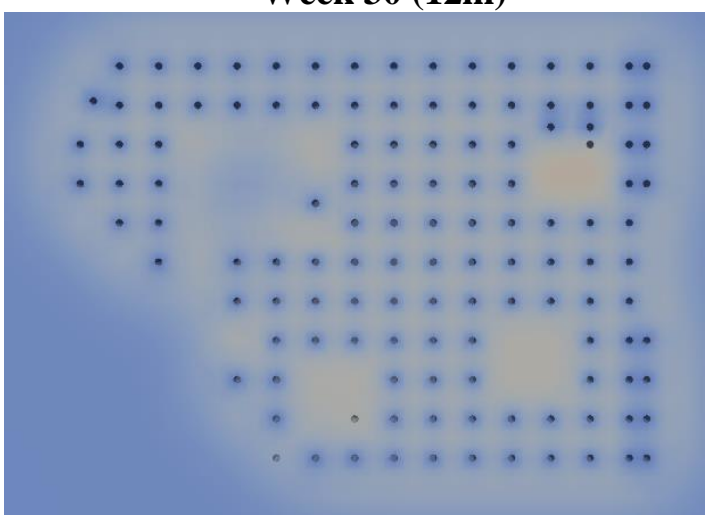

Week $70(6 \mathrm{~m})$

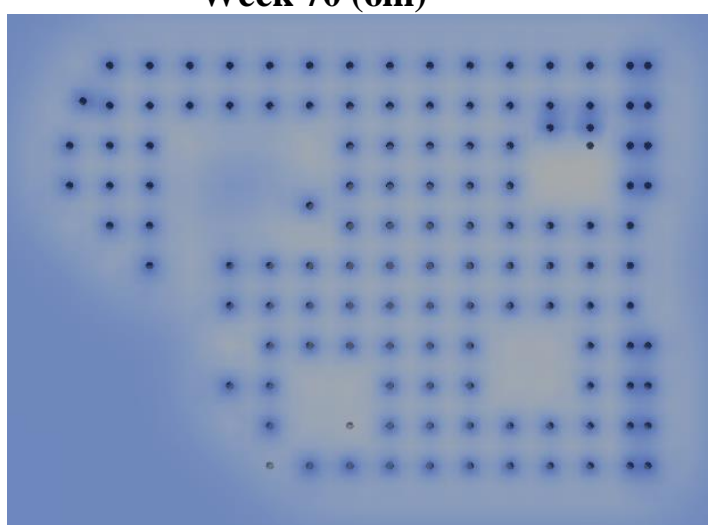

Week $70(9 \mathrm{~m})$

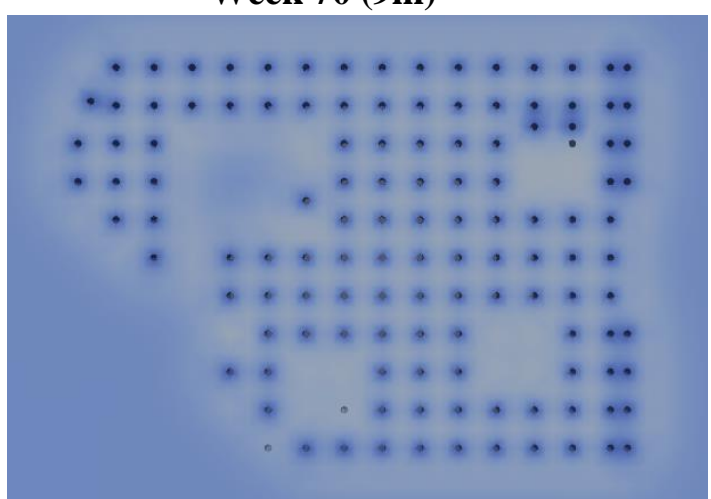

Week 70 (12m)

Temperature

$\begin{array}{lllllllllll}1.0 e+01 & 12 & 14 & 16 & 18 & 20 & 22 & 24 & 26 & 28 & 3.0 e+01\end{array}$

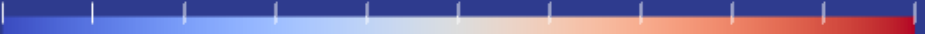

Figure 13. Temperature distribution in the ground with time and variation in pile distance 


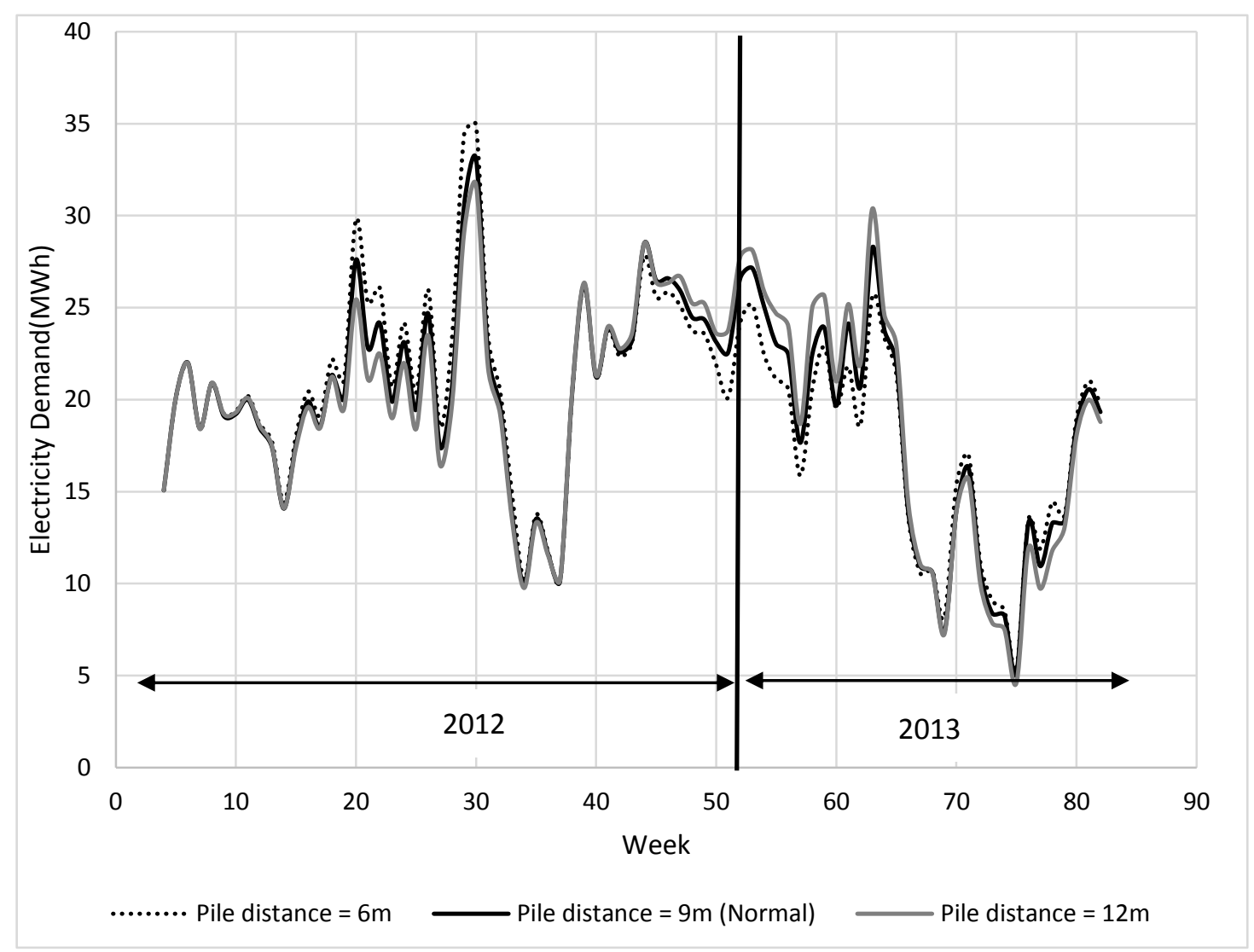

Figure 14. Changes in electricity demand with variation in pile distance

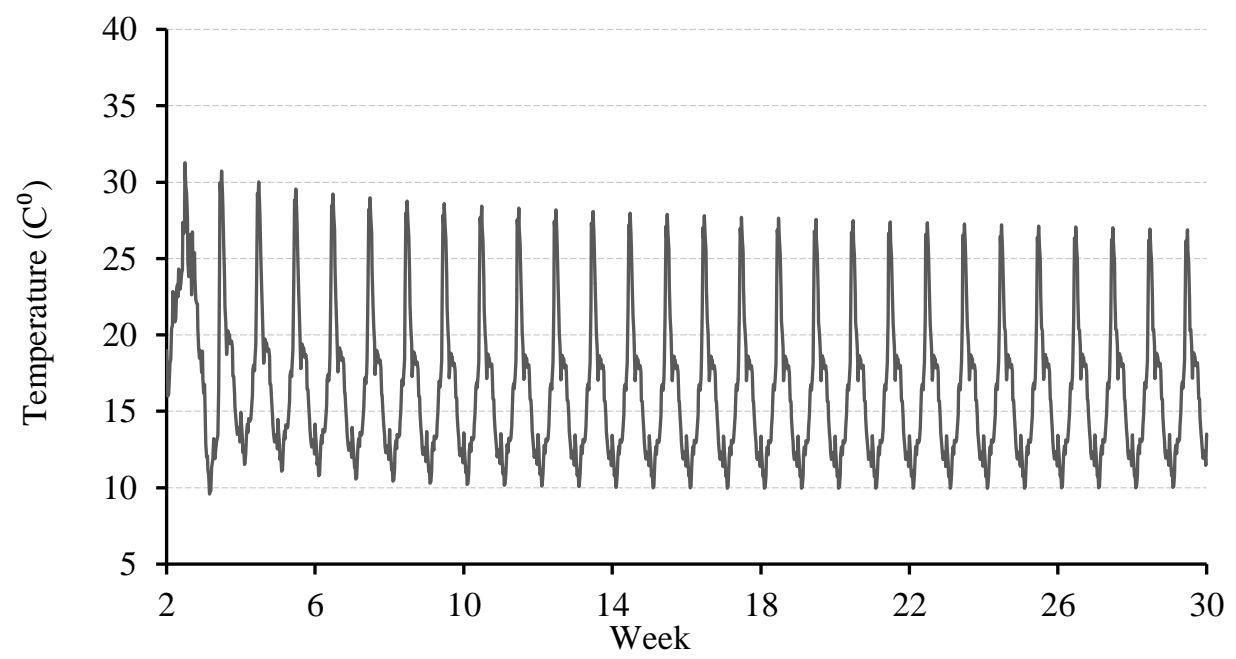

Figure 15. Predicted 30-year GHE-inlet temperature 


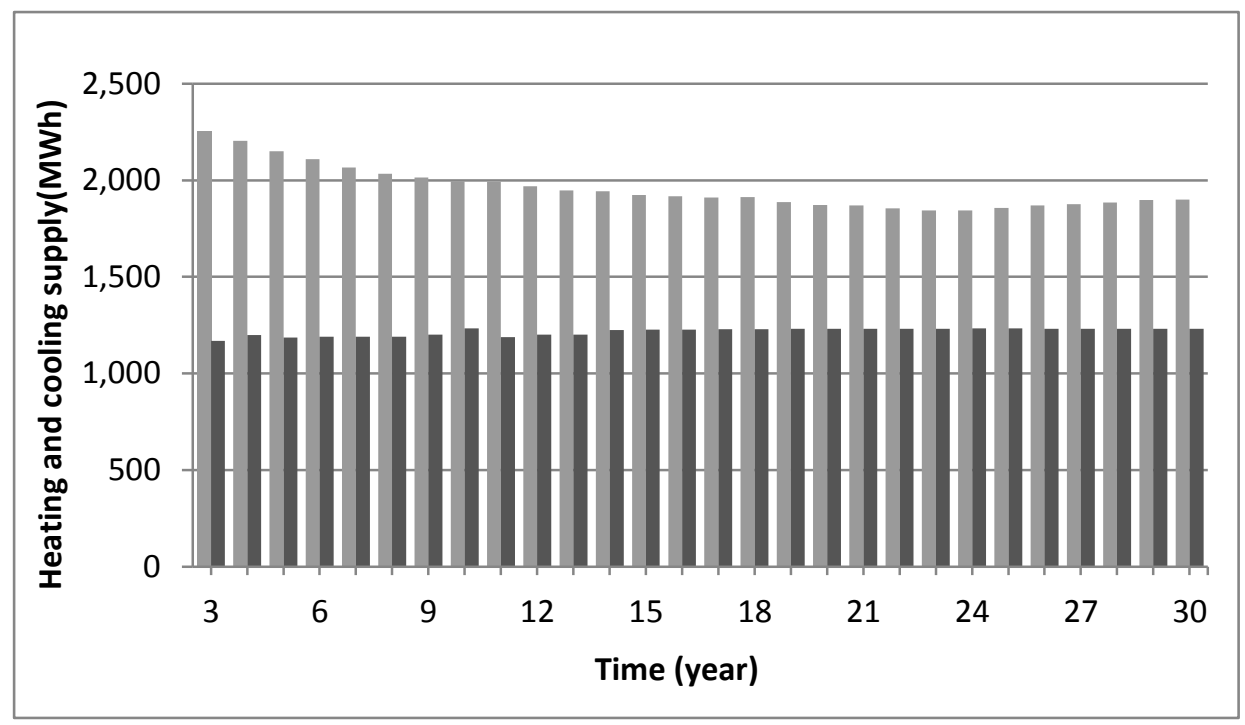

Figure 16. Projected 30-year annual heating (grey) and cooling (black) demand supplied by the GSHP;

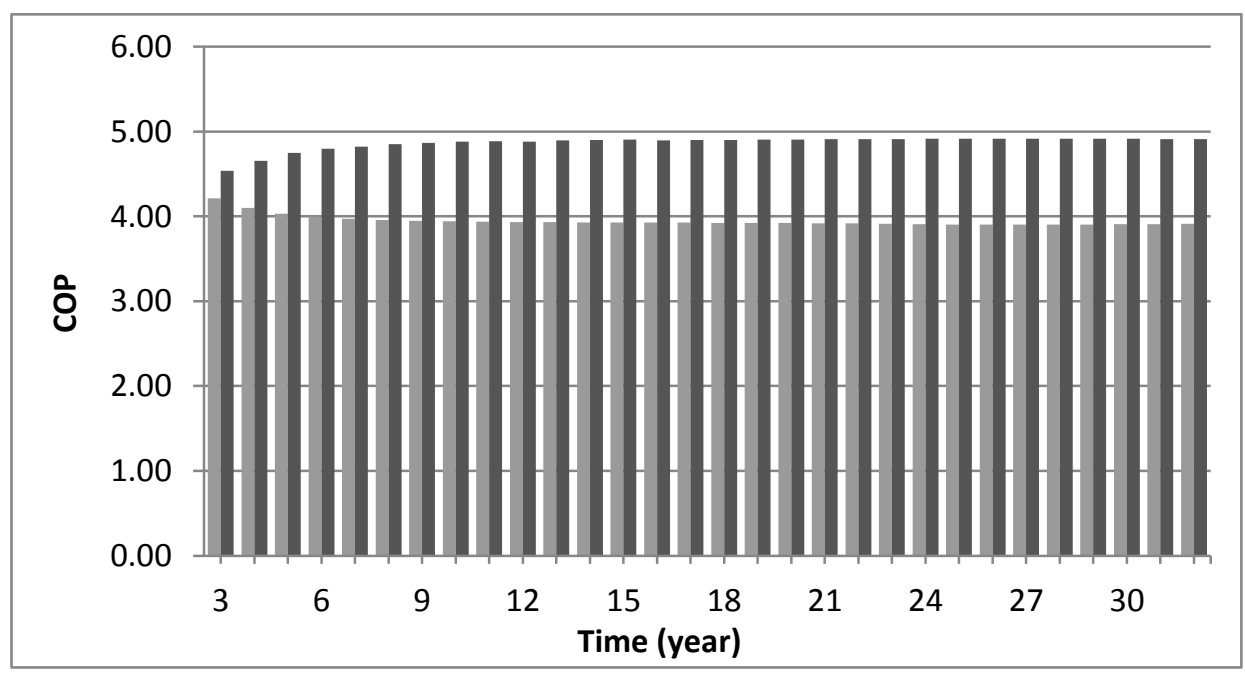

Figure 17. Projected 30-year annual heating (grey) and cooling (black) coefficients of performance 


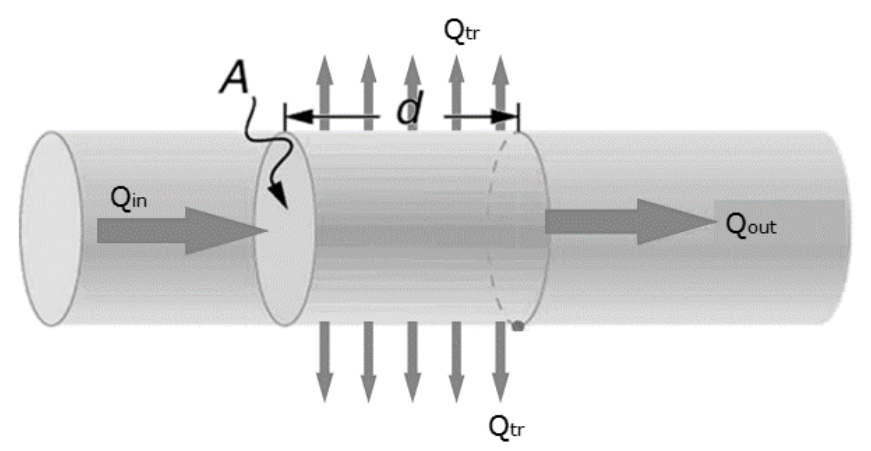

(a)

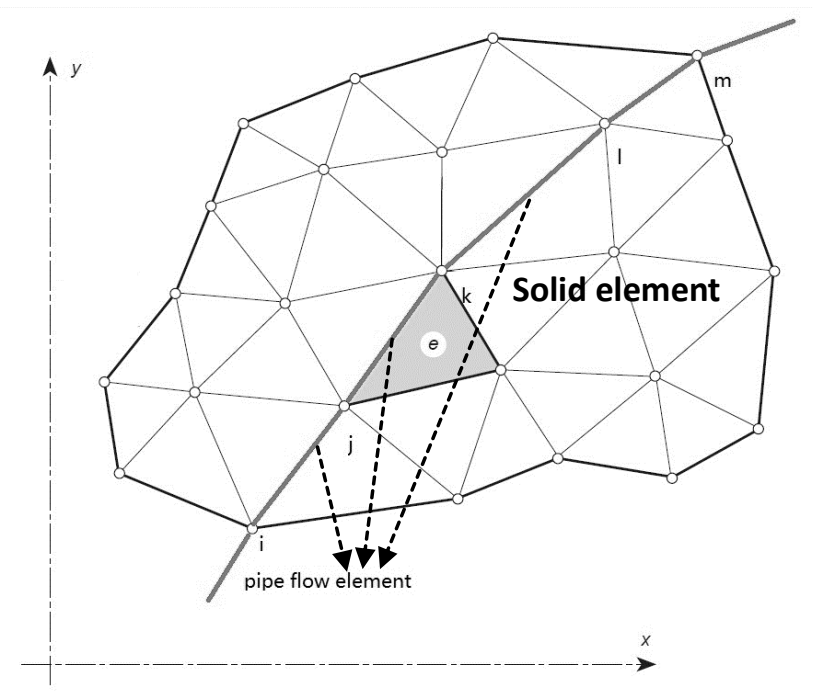

(b)

Figure A-1: (a) Mechanism of heat transfer in fluid flowing in a pipe; (b) Finite element model for heat transfer between pipe flow and concrete/soil 